\title{
Parada Cardiorrespiratória: caracterização do atendimento no serviço de atendimento móvel de urgência
}

RESUMO I Objetivo: descrever as características do atendimento às vítimas de parada cardiorrespiratória no ambiente préhospitalar. Métodos: estudo quantitativo, epidemiológico e retrospectivo elaborado a partir de dados presentes nas fichas de atendimento realizado pelo Serviço de Atendimento Móvel de Urgência, ocorridas no ano de 2014 referentes às vítimas de parada cardiorrespiratória. As informações foram coletadas através de formulário estruturado utilizando a linguagem Utstein e análise descritiva foi obtida após processamento dos dados no pacote estatístico STATA 12.0. Resultados: foram investigadas 946 fichas de atendimento por parada cardiorrespiratória. Entre as vítimas, houve predomínio do sexo masculino (56,3\%), com faixa etária de 61-80 anos (32,5\%), eventos de natureza clínica (80\%), o ritmo cardíaco prevalente foi a assistolia (42,2\%) e o óbito foi o principal desfecho (84,5\%). Conclusões: constatou-se a necessidade de treinamento direcionado à população, com o objetivo de reconhecer e intervir precocemente na parada cardiorrespiratória e em paralelo, aprimorar a anamnese durante telemedicina. Palavras-chaves: Parada Cardíaca; Reanimação Cardiopulmonar; Serviços médicos de Emergência; Enfermeiras e Enfermeiros.

\begin{abstract}
Objective: to describe the characteristics of assistance for victims of cardiopulmonary arrest in the prehospital setting. Methods: this is a quantitative, epidemiological and retrospective study made from data present in the medical files of the assistance provided by the Mobile Emergency Medical Service, occurred in 2014 regarding the victims of cardiopulmonary arrest. The information was collected through a structured form using the Utstein language and the descriptive analysis was obtained after processing the data in the STATA 12.0 statistical package. Results: 946 medical files for cardiopulmonary arrest were investigated. Among the victims, there was a predominance of males (56.3\%), aged $61-80$ years $(32.5 \%)$, events of a clinical nature $(80 \%)$, the prevalent cardiac rhythm was asystole $(42,2 \%)$ and death was the main outcome $(84.5 \%)$. Conclusions: it was found a need for training aimed at the population, with the aim of recognizing and intervening early in cardiopulmonary arrest and in parallel, improving anamnesis during telemedicine. Keywords: Heart arrest; Cardiopulmonary resuscitation; Emergency medical services; nurses.
\end{abstract}

RESUMEN | Objective: to describe the characteristics of assistance for victims of cardiopulmonary arrest in the prehospital setting. Methods: this is a quantitative, epidemiological and retrospective study made from data present in the medical files of the assistance provided by the Mobile Emergency Medical Service, occurred in 2014 regarding the victims of cardiopulmonary arrest. The information was collected through a structured form using the Utstein language and the descriptive analysis was obtained after processing the data in the STATA 12.0 statistical package. Results: 946 medical files for cardiopulmonary arrest were investigated. Among the victims, there was a predominance of males (56.3\%), aged 61-80 years (32.5\%), events of a clinical nature $(80 \%)$, the prevalent cardiac rhythm was asystole $(42,2 \%)$ and death was the main outcome (84.5\%). Conclusions: it was found a need for training aimed at the population, with the aim of recognizing and intervening early in cardiopulmonary arrest and in parallel, improving anamnesis during telemedicine.

Palavras claves: Heart arrest; Cardiopulmonary resuscitation; Emergency medical services; nurses.

\section{Paloma de Castro Brandão}

Enfermeira. Doutoranda em Saúde Coletiva pelo Instituto de Saúde Coletiva/UFBA. Escola de Enfermagem/UFBA, Departamento Enfermagem. ORCID: 0000-0002-8659-6292

\section{Itana Carvalho Nunes Silva}

Enfermeira. Mestra em Enfermagem pela Escola de Enfermagem/UFBA.

ORCID: 0000-0002-5045-6888

\section{Mariane Teixeira Dantas Farias}

Enfermeira. Mestra pela Escola Bahiana de Medicina e Saúde Pública. Faculdade de Tecnologia e Ciências. Departamento Medicina. ORCID: 0000-0003-4208-4911

\section{Victor Porfírio Ferreira Almeida Santos}

Enfermeiro. Mestre pelaEscola Enfermagem/ UFBA. Faculdade de Tecnologia e Ciências. Departamento Medicina.

ORCID: 0000-0002-7408-4150

\section{Dalmo Macedo França Farias}

Enfermeiro. Enfermeiro. Serviço de Atendimento Móvel de Urgência.

ORCID: 0000-0001-9390-7266

\section{Valdinei Sampaio Santa Cruz}

Estatístico. Serviço de Atendimento Móvel de Urgência.

ORCID: 0000-0001-8544-3158

\section{Josias Alves de Oliveira}

Enfermeiro. Mestrando pela Escola de Enfermagem/UFBA. Faculdade de Tecnologia e Ciências. Departamento Medicina. ORCID: 0000-0002-5100-5536

Recebido em: 14/07/2020

Aprovado em: 19/07/2020

\section{INTRODUÇÃO}

$\Lambda$ Parada Cardiorrespiratória (PCR) é uma das principais causas de morte em adultos no mundo moderno. ${ }^{(1)}$ As chaves para o tratamento da PCR são o reconhecimento precoce, o acionamento do serviço médico de emergência, o início das compressões torácicas e a desfibrilação precoce. ${ }^{(2,3,4)}$

Os quatro passos descritos anteriormente são considerados procedimentos de baixa complexidade, entretanto, a população brasileira não recebe treinamentos periódicos para reconhecer e conduzir as compressões torácicas até a chegada da equipe de emergência. As consequências geram baixas taxas de sobrevida que perpassam entre $1 \%$ 
e $6 \%,{ }^{(3)}$ relacionadas à fisiopatologia do evento, que tem um dos tempos mais críticos para ser atendido. Caso a realização das manobras de reanimação não ocorra com brevidade, após 3 a 5 minutos, a probabilidade de comprometimento neurológico aumenta significativamente. ${ }^{(1)}$

Desta maneira, o atendimento à PCR é revisto periodicamente por instituições acreditadas com a finalidade de aperfeiçoamento dos desfechos. Atualizações recentes aprimoram o atendimento telefônico por atendente regulador do Serviço Médico de Emergência, no Brasil denominado Serviço de Atendimento Móvel às Urgências (SAMU). Tais atualizações incluem o aumento da efetividade das instruções por telefone, sendo desta forma voltadas à qualidade das compressões torácicas para o público leigo. ${ }^{(2)}$ Instruções adequadas pelo despachante, ao telefone, e parada cardíaca assistida demonstram resultados promissores em locais públicos. ${ }^{(4)}$

A continuidade da assistência se dá, estrategicamente, com a chegada da equipe do SAMU, que inicia o atendimento com a realização de Suporte Básico e Avançado de Vida. O objetivo é aumentar a sobrevida do paciente, com a realização de intervenções precoces como a manutenção de compressões torácicas efetivas, uso de via aérea avançada, medicações específicas para cada caso, e, com o sucesso da reanimação, encaminhamento para uma unidade hospitalar que possa dar continuidade ao tratamento. ${ }^{(5)}$

A importância em descrever as características do atendimento às vítimas de PCR no ambiente pré-hospitalar na quarta capital mais populosa do país está embasada na elevada ocorrência de eventos cardiovasculares, na necessidade de se obter informações sobre este fenômeno e subsídios para aumentar as chances de sobrevivência das vítimas de PCR neste meio.

Considerando a relevância da temática para qualificação da atenção no

\section{6}

A importância em descrever as características do atendimento às vítimas de PCR no ambiente préhospitalar na quarta capital mais populosa do país está embasada na elevada ocorrência de eventos cardiovasculares, na necessidade de se obter informações sobre este fenômeno e subsídios para aumentar as chances de sobrevivência das vítimas de PCR neste meio. âmbito da urgência e emergência, foi traçado como objetivo: descrever as características do atendimento às vítimas de PCR no ambiente pré-hospitalar.

MÉTODOS

Trata-se de estudo quantitativo, de caráter epidemiológico e retrospectivo realizado a partir da extração de dados das fichas de atendimento às vítimas de PCR atendidas pelas unidades de suporte básico de vida (SBV) e suporte avançado de vida (SAV) do SAMU, do município de Salvador-Ba, Brasil.

O referido serviço deu início às suas atividades em 18 de julho de 2005, sob a égide da Secretaria Municipal de Saúde, que realiza cobertura assistencial a uma população estimada de 2.872.347 habitantes. ${ }^{(6)}$ Sua estrutura conta com uma central de regulação das urgências, 33 unidades de SBV, 08 unidades de SAV, 01 unidade móvel fluvial e 08 motocicletas $^{(7)}$.

Utilizou-se como critério de inclusão para coleta de dados, fichas de pacientes atendidos pelo SAMU, geradas no período de 01 de janeiro a 31 de dezembro de 2014, com chamado ou apelido da ocorrência, intitulado pelos seguintes termos: 'parado', 'não responde', 'inconsciente' ou 'PCR'. Foram conferidas todas as fichas do ano de 2014 e separadas manualmente todas as que se tratavam de atendimentos descritos pelos critérios de inclusão.

A coleta dos dados ocorreu no período de fevereiro a março de 2015 por enfermeiros do referido serviço, mediante uso de formulário estruturado. O formulário estruturado de coleta foi elaborado com base na linguagem Utstein Out-of-hospital, ${ }^{(8)}$ instrumento que direciona a coleta de dados relacionadas à PCR, validado no Brasil. Ademais, foi ajustado conforme os dados disponíveis nas fichas de atendimento do SAMU, as quais foram preenchidas por técnicos de enfermagem, enfermeiros e médicos. $\mathrm{O}$ instrumento utilizado para 
a coleta dos dados foi inicialmente testado com as fichas de atendimento do ano de 2013

Tabela 1 - Caracterização das vítimas de PCR do SAMU. Salvador- Ba, 2014, (n= 946).

\begin{tabular}{lcc}
\hline Variável & N & $\%$ \\
\hline Sexo & 533 & 56,3 \\
\hline Masculino & 374 & 39,6 \\
\hline Feminino & 39 & 4,1 \\
\hline Sem informação & & \\
\hline Idade & 5 & 0,5 \\
\hline $0-1$ & 24 & 2,5 \\
\hline $2-20$ & 93 & 9,8 \\
\hline $21-40$ & 240 & 25,4 \\
\hline $41-60$ & 308 & 32,6 \\
\hline $61-80$ & 197 & 20,8 \\
\hline $81-100$ & 79 & 8,4 \\
\hline Sem informação & & \\
\hline Etiologia da PCR & 20 & 80,0 \\
\hline Clínica & 757 & 17,8 \\
\hline Traumática & 168 & 0,1 \\
\hline Psiquiátrica & 01 & 2,1 \\
\hline Sem informação & 20 & \\
\hline Fontei & & \\
\hline
\end{tabular}

Fonte: elaboração própria, 2015.

\section{Tabela 2- Realização de RCP pelo SAMU. Salvador- Ba, 2014 ( $\mathrm{n=946)}$.}

Variável

Realização de RCP

$\begin{array}{lcc}\text { Sim } & 369 & 39,0 \\ \text { Não } & 562 & 59,4 \\ \text { Sem informação na ficha } & 15 & 1,6\end{array}$

Fonte: elaboração própria, 2015.

Tabela 3 - Primeiro ritmo detectado no atendimento às vítimas de PCR pelo SAMU. Salvador- Ba, $2014(n=369)$.

\section{Variável}

N

$\%$

Primeiro ritmo detectado

\begin{tabular}{lcc}
\hline Assistolia & 156 & 42,3 \\
\hline Atividade Elétrica sem Pulso & 25 & 6,8 \\
\hline Fibrilação ventricular & 44 & 11,9 \\
\hline Taquicardia ventricular sem pulso & 16 & 4,3 \\
\hline Sem informação & 128 & 34,7
\end{tabular}

Fonte: elaboração própria, 2015 dados clínicos (primeiro ritmo cardíaco detectado), procedimentos realizados (se houve reanimação cardiovascular-RCP), levantamento sobre a sobrevida imediata e óbitos e o tempo de realização de RCP investidos pelas equipes de SBV ou SAV. Os dados relacionados ao acionamento, no que diz respeito às recomendações do médico regulador ao solicitante, não estavam disponíveis na ficha de atendimento. Os dados consolidados formaram um banco no programa Microsoft Excel, sendo exportados para o pacote estatístico STATA, versão 12.0, no qual as análises foram processadas em frequências relativas e absolutas.

O desenvolvimento da pesquisa se deu mediante a aprovação do projeto pelo Comitê de Ética em Pesquisa da Faculdade de Medicina da Bahia (FMB), da Universidade Federal da Bahia, mediante parecer CAAE n 55279216.1.0000.5577. Este estudo foi financiado e custeado pelos pesquisadores.

\section{RESULTADOS}

A partir de 14.400 fichas correspondentes aos atendimentos realizados no ano de 2014, foram selecionadas 946 fichas referentes a todos os atendimentos de pacientes vítimas de PCR pelo SAMU, no município de Salvador- Ba. Entre as vítimas de PCR, houve predomínio do sexo masculino $(56,3 \%)$, com faixa etária de 61-80 anos (32,6\%), a etiologia da $\mathrm{PCR}$, predominou as de natureza clínica (80\%) (tabela 1).

Quanto aos procedimentos, dispostos na tabela 2, a RCP foi realizada em $39 \%$ dos casos. Em 59,4\% não foi realizada RCP e em 1,6\% das fichas os profissionais registraram o óbito sem referir se a RCP foi ou não realizada.

Conforme a tabela 3, os dados clínicos dos atendimentos em que se realizou a RCP ( $n=369)$, o primeiro ritmo cardíaco detectado foi a assistolia (42,3\%), seguida de fibrilação ventricular (11,9\%). Em 34,7\% das fichas não houve registro do primeiro ritmo detectado. 
Com relação aos desfechos dos atendimentos, o óbito se perfez como principal resultado, mesmo após intervenção do SBV (45,3\%) e SAV (39,3\%). Em 48 (13\%) atendimentos em que a RCP foi realizada, os pacientes apresentaram sobrevida imediata com retorno à circulação espontânea (tabela 4).

O tempo de realização de RCP no SBV foi inferior a 20 minutos $(32,2 \%)$, já no SAV o tempo de assistência em RCP foi superior a 20 minutos em $(32,2 \%)$, conforme (tabela 5$)$.

\section{DISCUSSÃO}

O predomínio de usuários do sexo masculino, entre as vítimas de PCR no ambiente pré-hospitalar, está em consonância com três estudos análogos realizados no Brasil (Belo Horizonte,
Londrina e em Porto Alegre) e dois na Espanha. ${ }^{(9,10,11,12,13)}$ Quando a análise desta variável é feita no ambiente intra-hospitalar especializado em cardiopneumologia de alta complexidade, observa-se a prevalência do sexo masculino entre as vítimas de PCR. ${ }^{(14)}$

A alta frequência de chamados clínicos constatada converge com os dados encontrados em outras unidades da federação, referentes aos grupos etários de 41-60 e 61-80 anos. Um estudo realizado em Londrina, ${ }^{(9)}$ indicou incidência de casos clínicos em 77,3\% dos atendimentos do SAMU, corroborando nas semelhanças quanto às causas do chamado e as faixas etárias predominantes em Salvador. Justifica-se tal relação pela alta prevalência de doenças crônicas não transmissíveis do aparelho circulatório no estado da Bahia, que de

Tabela 4. Desfechos dos atendimentos ás vítimas PCR pelo SAMU. Salvador- Ba, $2014(n=369)$.

\begin{tabular}{lcc} 
Variável & $\mathrm{N}$ & $\%$ \\
\hline Desfecho dos atendimentos & & 45,3 \\
\hline Óbito após manobras de SBV & 167 & 39,3 \\
\hline Óbito após manobras de SAV & 145 & 13 \\
\hline Sobrevida imediata & 48 & 1,4 \\
\hline Óbito sinais evidentes incompatíveis com a vida & 5 & 1 \\
\hline Sem informação & 4 &
\end{tabular}

Fonte: elaboração própria, 2015.

Tabela 5. Tempo de realização de RCP dispendidos durante atendimentos às vítimas de PCR pelo SAMU. Salvador- Ba, 2014 (n=369).

\section{Variável}

Tempo de SBV

0-20 minutos

Mais de 20 minutos

Mais de 30 minutos

Sem informação

Tempo de SAV

0-20 minutos

\section{N}

$\%$

Mais de 20 minutos

Mais de 30 minutos

Sem informação

Fonte: elaboração própria, 2015 acordo com o DATASUS, segue a tendência nacional. ${ }^{(15)}$

A cobertura populacional de 30,2\% de ações da atenção básica e 23,8\% da estratégia saúde da família em Salvador no mesmo ano da pesquisa, ${ }^{(15)}$ aliada a alta prevalência de doenças crônicas não transmissíveis, indicam a necessidade de investimento e fortalecimento em ações de prevenção e promoção no primeiro nível da atenção à saúde, com intuito de minimizar eventos de agudização das comorbidades, contribuindo para a redução do número de mortes evitáveis. O SAMU, neste sentido, atua como um observatório da rede, traçando diagnóstico situacional das deficiências do sistema de saúde dos diversos territórios regionais. ${ }^{(16,17)}$

Outro dado evidenciado pelo estudo em tela, diz respeito a não realização de compressões cardíacas por leigos, revelando que há desinformação/ desconhecimento da população na identificação dos sinais de PCR, gerando atrasos no atendimento à vítima e no tempo resposta do acionamento ao chamado telefônico. Tal dado, reforça recomendação da Sociedade Brasileira de Cardiologia, quanto a necessidade de melhorias nas estruturas e no sistema de saúde, propondo a criação de programas que visem treinar a população, fornecer materiais e disponibilizar desfibrilador externo automático (DEA) em locais públicos com alta movimentação de pessoas. ${ }^{(18,19)}$

Por outro lado, tais questões evidenciam a importância do papel exercido pelo médico regulador no atendimento telefônico primário, no momento de determinar o diagnóstico sindrômico. Nos casos potenciais de PCR, este profissional deve atuar mais efetivamente junto à população, orientando na realização das manobras de RCP com ênfase nas compressões cardíacas, até a chegada do serviço móvel. As atualizações das diretrizes ${ }^{(18,19)}$ recomendam estas ações, como uma possível melhoria nos desfechos da PCR. 
Tais diretrizes ${ }^{(2,5,18)}$ foram atualizadas e estudos recentes, ${ }^{(19)}$ reforçam a necessidade de intensificar as ações educativas direcionadas à população leiga. Estas visam aperfeiçoar a probabilidade de que as vítimas de PCR recebam cuidados de mais alta qualidade, baseados em evidências, onde os treinamentos em RCP utilizem princípios educacionais respaldados por pesquisas que traduzam o conhecimento científico em prática. ${ }^{(19,20)}$

A simplificação das manobras, direcionadas à população leiga foram introduzidas em 2010, quando se excluiu na avaliação inicial a etapa do "ver-ouvir-sentir" e, na modificação da sequência do suporte básico de vida de ABC para $\mathrm{CAB}$, enfatizando a importância das compressões torácicas de qualidade o mais precoce possível. Manobras de ventilação para o leigo se tornaram irrelevantes, bem como a etapa de checar pulso. ${ }^{(18,19)}$

Tais recomendações, têm o objetivo de facilitar o aprendizado e aumentar o contingente de leigos treinados, considerando o risco da população em não absorver tantas etapas. A assistência ofertada pela população leiga pode ser caracterizada como um cuidado desprovido de recursos, pois nesse momento não existem profissionais na cena, aparelhos médico-hospitalar e medicamentos envolvidos. ${ }^{(18)}$

No serviço pré-hospitalar, a solicitação de socorro se dá via telefone, o gerenciamento da chamada acontece através de uma central de regulação composta minimamente por telefonistas e médicos reguladores, resultando em posterior orientação ao solicitante ou acionamento de uma equipe de saúde móvel para o atendimento. A unidade enviada pode ser de SBV ou de SAV, com o objetivo de chegar precocemente à vítima e prestar atendimento qualificado. Esses aspectos normativos estão bem descritos em portarias, mas os critérios de urgência costumam variar muito a partir da comunicação entre médico regulador com quem solicita o atendimento. $^{(16)}$

Em relação a uma solicitação de atendimento à vítima de PCR, merecem destaque as condições de trafegabilidade da capital baiana. Houve um crescimento acentuado da taxa de motorização da população, da frota de ônibus urbano e de transporte alternativo. Todos esses entraves, aliados à inexistência de um sistema de transporte de massa (metrô), desorganizam o trânsito, gerando interferências no aumento do tempo-resposta de atendimento do SAMU. Em 2014, a maior parte das principais vias da cidade passava por obras estruturais, em vista de sediar um evento esportivo mundial e as obras do metrô ainda não estavam finalizadas.

Neste estudo, predominou o óbito como principal desfecho dos atendimentos as vítimas de PCR, mesmo após ações isoladas do SAV e SBV, corroborando resultados encontrados em três estudos realizados em Londrina, Belo Horizonte, Porto Alegre, e dois na Espanha. ${ }^{(9,10,11,12,13)}$ Os estudos confirmaram que, apesar de consideráveis esforços e avanços atingidos na última década, no campo da prevenção, tratamento e através de estratégias que aumentam as possibilidades de êxito na RCP, a sobrevivência da PCR extra-hospitalar continua sendo baixa.

A assistolia, como ritmo constatado mais frequente neste estudo, reflete os resultados da associação dos dados discutidos anteriormente, destacando-se os atrasos nos pedidos de ajuda e o alargado tempo de deslocamento das unidades móveis para a realização do atendimento. Neste estudo, a mediana do tempo resposta (TR) foi de 25,5 minutos. Em comparação a dois estudos brasileiros realizados em Porto Alegre (TR-13 minutos) e em Belo Horizonte (TR-09 minutos) seus resultados indicam que, apesar da existência de outros fatores agregados, o elevado TR pode ter contribuído para o compro- metimento da sobrevida das vítimas de PCR. ${ }^{(10,11)}$ Outros dois estudos espanhóis atribuíram a menor incidência de ritmos chocáveis na PCR extra-hospitalar ao atraso na gestão do alerta de chamada, a ativação do equipamento de emergência e os cuidados no local da ocorrência, em conjunto com outros fatores. ${ }^{(12,13)}$

Os três primeiros elos da cadeia de sobrevida do atendimento à PCR extra-hospitalar são direcionados aos socorristas leigos. A American Heart Association, em 2015 destacou a importância destas pessoas, lotadas nas comunidades em: reconhecer a PCR, pedir por ajuda, iniciar a RCP e aplicar a desfibrilação, ou seja, ter acesso público a um DEA, até que uma SBV consiga chegar, assumindo os cuidados. ${ }^{(18,19)}$

$\mathrm{O}$ algoritmo do SBV, conta com a presença de socorristas treinados, DEA, além de outros recursos disponíveis na ambulância, tais como: dispositivos para as insuflações ventilatórias como o bolsa-válvula-máscara, oxigênio e a possibilidade de receber orientações do médico regulador, através da central de regulação do SAMU.

\section{CONCLUSÃO}

Os resultados encontrados possibilitaram apontar para a necessidade de intervenção em diversos campos: qualificação de pessoas, utilização de estratégias e ferramentas que diminuam o TR para iniciar SBV direcionada à população, com o objetivo de reconhecimento precoce da PCR, acionamento do SAMU e a atuação na RCP de forma mais efetiva. A instalação do DEA em comunidades pode aproximar o público do SAMU, bem como aumentar a sobrevida imediata das vítimas de PCR.

Este estudo destacou a importância da reorganização dos serviços para o atendimento de qualidade, bem como o aprimoramento do teleatendimento médico, considerando uma comuni- 
cação efetiva, simples e a garantia do envio do suporte de vida necessário, aumentando chances de sobrevida até a chegada do atendimento móvel. Reconhecemos como limitação do estudo o fato dos achados estarem circunscritos a um município e o incompleto preenchimento das fichas de atendimento, impossibilitando o levantamento de dados de modo mais efetivo e robusto.

Entende-se que, essa pesquisa se faz importante para a enfermagem, uma vez que, permitiu contribuir para novas reflexões sobre o cuidado em emergência. A elaboração de estra- tégias de ação baseadas: no trabalho em rede, na perspectiva da interdisciplinaridade e intersetorialidade frente a uma emergência cardiovascular, favorecerão a disseminação de informações e ações frente a uma PCR, potencializando todos como atores do cuidado em saúde.

\section{Referências}

1. Boladeres IB, Jordi D. Reanimación cardiopulmonar extrahospitalaria / Out-of-hospital cardiopulmonary resuscitation. Emergencias (Sant Vicenç dels Horts). 2020 [acesso: 16/07/2020]; 32 (2): 146-7. Disponivel em: http:// emergencias.portalsemes.org/descargar/reanimacin-cardiopulmonar-extrahospitalaria/

2. AHA. Destaques das Atualizações Específicas das Diretrizes de 2017 da American Heart Association para Suporte Básico de Vida em Pediatria e para Adultos e Qualidade da Ressuscitação Cardiopulmonar. 2017 [acesso: 16/07/2020]. Disponivel em: https://eccguidelines.heart.org/wp-content/ uploads/2017/12/2017-Focused-Updates_Highlights_PTBR.pdf

3. Guimarães HP, Olivato GB, Pispico A. Ressuscitação cardíaca pré-hospitalar. Do pré-hospitalar à sala de emergência: minutos que salvam uma vida - suporte básico. Rev. Soc. Cardiol. 2018 [acesso:16/07/2020] ; 28 (3). Disponível em: https://pesquisa.bvsalud.org/portal/resource/pt/biblio-916547 4. Shimamoto T, Kiyohara K, Matsuyama T, et al. Impact of Bystander Cardiopulmonary Resuscitation and Dispatcher Assistance on Survival After Out-of-Hospital Cardiac Arrest Among Adult Patients by Location of Arrest. Int Heart J. 2020; [acesso: 16/07/2020]; 61 (1): 46-53. Disponível em: https:// www.jstage.jst.go.jp/article/ihj/61/1/61_19-301/_pdf/-char/en

5. AHA. Destaques das Atualizações Direcionadas nas Diretrizes de 2019 da American Heart Association para Ressuscitação Cardiopulmonar e Atendimento Cardiovascular de Emergência. 2019. [acesso em: 16/07/2020]. Disponível em: https://eccguidelines.heart.org/wp-content/uploads/2019/11/ 2019-Focused-Updates_Highlights_PTBR.pdf

6. Instituto Brasileiro de Geografia e Estatística (IBGE). Cidades. Brasília: Ministério da Economia; 2019 [acesso: 26/10/2019]; Disponível em: https:// cidades.ibge.gov.br/brasil/ba/salvador/panorama

7. Brasil. Portaria: 2.908 , de 19 de setembro de 2018. Renova a qualificação e especifica a composição do incentivo de custeio da Central de Regulação das Urgências, das Unidades de Suporte Básico (USB), Unidades de Suporte Avançado (USA), Unidade Móvel Fluvial (Ambulancha) e Unidades de Veículos Motocicletas (motolâncias) do Município de Salvador (BA), pertencentes ao Serviço de Atendimento Móvel de Urgência (SAMU 192). Diário Oficial [da] República Federativa do Brasil. 2018 [acesso: 05/06/2019]. Disponível em: http://www.in.gov.br/materia/-/asset_publisher/Kujrw0TZC2Mb/content/id/41779982/do1-2018-09-21-portaria-n-2-908-de-19-de-setembrode-2018-41779659

8. Perkins GD, Jacobs IG, Nadkarni VM, Berg RA, Farhan B, et al. Cardiac Arrest and Cardiopulmonary Resuscitation Outcome Reports: Update of the Utstein Resuscitation Registry Templates for Out-of-Hospital Cardiac Arrest. Circulation. 2015 [acesso: 11/12/2015]; 132 (13): 1286-1300. Disponível em: https://www.ahajournals.org/doi/10.1161/CIR.0000000000000144 9. Zandomenighi RC, Martins EAP. Análise epidemiológica dos atendimentos de parada cardiorrespiratória. Revista de Enfermagem UFPE On Line. 2018 [acesso:21/08/2019]; 7 (12): 1912-22. Disponível em: https://periodicos. ufpe.br/revistas/revistaenfermagem/article/view/230822/29470

10. Morais DA, Carvalho DV, Correa AR. Parada cardíaca extra-hospitalar: fatores determinantes da sobrevida imediata após manobras de ressuscitação cardiopulmonar. Revista Latino-Americana de Enfermagem. 2014 [acesso: 23/07/2018]; 22 (4): 562-8. Disponivel em: https://www.scielo.br/pdf/rlae/ v22n4/pt_0104-1169-rlae-22-04-00562.pdf
11. Semensato G, Zimerman L, Rohde LE. Avaliação inicial do Serviço de Atendimento Móvel de Urgência na Cidade de Porto Alegre. Arquivos Brasileiros de Cardiologia. 2011 [acesso: 25/07/2018]; 96 (3): 196-204. Disponível em: https://www.scielo.br/pdf/abc/v96n3/aop00911.pdf

12. Ballesteros-Peña S. Variabilidad circadiana en la frecuencia de episodios extrahospitalarios de parada cardiorrespiratoria. Cardiocore. 2015 [acesso: 20/01/2019]; 50 (1): 27-33. Disponivel em: https://www.researchgate.net/ publication/271967411_Variabilidad_circadiana_en_la_frecuencia_de_ episodios_extrahospitalarios_de_parada_cardiorrespiratoria

13. López-Messa JB, Alonso-Fernández Jl, Andrés-de Llano JM, Garmendia-Leiza JR, Ardura-Fernández J, Castro-Rodríguez F, et al. Circadian rhythm and time variations in out-hospital sudden cardiac arrest. Medicina Intensiva. 2012 [acesso 28/07/2018]; 36 (6): 402-9. Disponível em: https:// www.medintensiva.org/en-circadian-rhythm-time-variations-in-articulo-S2173572712001075

14. Santana-Santos E, Bezerra DG, Alberto MR, Ferreira FG, Palomo JSH, Silva $C C B$, et al. Perfil de atendimentos do código azul em um hospital escola especializado em cardiopneumologia. Revista Cubana de Enfermería. 2017 [acesso: 23/01/2019]; 33 (1): [aprox. 0 p.]. Disponível em: http://www.revenfermeria.sld.cu/index.php/enf/article/view/705

15. Datasus. Indicadores de morbidade: planilha com série histórica com indicadores do Grupo D para o Brasil e regiões. Brasília: Distrito Federal, 2016 [acesso: 28/08/2016]. Disponível em: http://tabnet.datasus.gov.br/cgi/ idb2012/matriz.htm\#morb

16. O'Dwyer G, Konder MT, Reciputti LP, Macedo C, Lopes MGM. 0 processo de implantação do Serviço de Atendimento Móvel de Urgência no Brasil: estratégias de ação e dimensões estruturais. Cad. Saúde Pública. 2017 [acesso: 27/07/2018]; 33 (7): e00043716. Disponível em: https://www.scielo.br/pdf/ csp/v33n7/1678-4464-csp-33-07-e00043716.pdf

17. Neves RG, Flores TR, Duro SMS, Nunes BP, Tomasi E. Time trend of Family Health Strategy coverage in Brazil, its Regions and Federative Units, 20062016. Epidemiol. Serv. Saude. 2018 [acesso 02/08/2019]; 27 (3): e2017170. Disponível em: https://scielosp.org/pdf/ress/2018.v27n3/e2017170/en 18. Hazinski MF, Shuster M, Donnino MW, Travers AH, Samson RA, Schexnayder SM, et al. Destaques da American Heart Association 2015: Atualização das Diretrizes de RCP e ACE. American Heart Association, 2015 [acesso:16/01/2016]; p. 1-32, 2015. Disponivel em: https://eccguidelines. heart.org/wp-content/uploads/2015/10/2015-AHA-Guidelines-Highlights-Portuguese.pdf

19. Bernoche C, Timerman S, Polastri TF, Giannetti NS, Siqueira AWS, Piscopo A, et al. Atualização da Diretriz de Ressuscitação Cardiopulmonar e Cuidados Cardiovasculares de Emergência da Sociedade Brasileira de Cardiologia - 2019. Arq. Bras. Cardiol. 2019 [acesso:16/01/2016]; 113 (3): 449-663. Disponivel em: https://www.scielo.br/pdf/abc/v113n3/0066-782X-abc-113-03-0449.pdf

20. Pitteri JSM, Monteiro PS. Caracterização do Serviço de Atendimento Móvel de Urgência ( SAMU ) em Palmas-Tocantins, Brasil, em 2009 [acesso: 25/07/2018]. Com. Ciências Saúde. 21 (3): 227-36. Disponível em: http:// bvsms.saude.gov.br/bvs/artigos/caracterizacao_servico_atendimento_movel.pdf 